\title{
Substrate quality alters the microbial mineralization of added substrate and soil organic carbon
}

\author{
S. Jagadamma ${ }^{1,2}$, M. A. Mayes ${ }^{1,2}$, J. M. Steinweg ${ }^{2,3,4}$, and S. M. Schaeffer ${ }^{5}$ \\ ${ }^{1}$ Environmental Sciences Division, Oak Ridge National Laboratory, Oak Ridge, TN 37831, USA \\ ${ }^{2}$ Climate Change Science Institute, Oak Ridge National Laboratory, Oak Ridge, TN 37831, USA \\ ${ }^{3}$ Biosciences division, Oak Ridge National Laboratory, Oak Ridge, TN 37831, USA \\ ${ }^{4}$ Department of Biological Sciences, University of Wisconsin-Baraboo/Sauk County, Baraboo, WI 53913, USA \\ ${ }^{5}$ Department of Biosystems Engineering and Soil Science, University of Tennessee, Knoxville, TN 37996, USA \\ Correspondence to: S. Jagadamma (jagadammas@ornl.gov)
}

Received: 22 October 2013 - Published in Biogeosciences Discuss.: 21 March 2014

Revised: 16 June 2014 - Accepted: 4 July 2014 - Published: 3 September 2014

\begin{abstract}
The rate and extent of decomposition of soil organic carbon (SOC) is dependent, among other factors, on substrate chemistry and microbial dynamics. Our objectives were to understand the influence of substrate chemistry on microbial decomposition of carbon (C), and to use model fitting to quantify differences in pool sizes and mineralization rates. We conducted an incubation experiment for 270 days using four uniformly labeled ${ }^{14} \mathrm{C}$ substrates (glucose, starch, cinnamic acid and stearic acid) on four different soils (a temperate Mollisol, a tropical Ultisol, a sub-arctic Andisol, and an arctic Gelisol). The ${ }^{14} \mathrm{C}$ labeling enabled us to separate $\mathrm{CO}_{2}$ respired from added substrates and from native SOC. Microbial gene copy numbers were quantified at days 4, 30 and 270 using quantitative polymerase chain reaction (qPCR). Substrate $C$ respiration was always higher for glucose than other substrates. Soils with cinnamic and stearic acid lost more native SOC than glucose- and starchamended soils. Cinnamic and stearic acid amendments also exhibited higher fungal gene copy numbers at the end of incubation compared to unamended soils. We found that 270 days were sufficient to model the decomposition of simple substrates (glucose and starch) with three pools, but were insufficient for more complex substrates (cinnamic and stearic acid) and native SOC. This study reveals that substrate quality exerts considerable control on the microbial decomposition of newly added and native SOC, and demonstrates the need for multi-year incubation experiments to constrain decomposition parameters for the most recalcitrant fractions of SOC and complex substrates.
\end{abstract}

\section{Introduction}

Three major processes influencing the rate and extent of microbial decomposition of soil organic carbon (SOC) are chemistry of carbon (C) inputs, inaccessibility of SOC to microbes and/or enzymes due to physical protection, and chemical binding of SOC with mineral matrices (Sollins et al., 1996; Schmidt et al., 2011; Schnitzer and Monreal, 2011). Three hypotheses are used to explain the decomposition of fresh $\mathrm{C}$ according to chemistry (Wickings et al., 2012): (i) chemical convergence, (ii) initial litter quality, and (iii) decomposer control. The chemical convergence hypothesis suggests that regardless of the differences in substrate quality and microbial diversity, all C substrates undergo decomposition through a limited number of biochemical pathways and reactions resulting in SOC of homogeneous chemistry (McGill, 2007; Fierer et al., 2009) and it supports the general understanding that simple sugars and amino acids are preferentially decomposed over complex lignin and lignocellulose. However, recent studies have also identified simple biopolymers of plant and microbial origin in stabilized SOC (Sutton and Sposito, 2005; Kelleher and Simpson, 2006), which indicates that chemical convergence hypothesis does not always dominate. According to the initial litter quality hypothesis, the chemical composition of substrates at the start of the decomposition process exhibits a strong influence on decomposition rate, therefore the chemistry of resultant stabilized SOC is more heterogeneous than for hypothesis (i) (Angers and Mehuys, 1990; Berg and McClaugherty, 2008). 
The decomposer control hypothesis suggests that distinct decomposer communities impose constraints on substrate decomposition, regardless of the difference in the quality of the substrate and the stage of decomposition (Strickland et al., 2009a; Wickings et al., 2011). Wickings et al. (2012) analyzed these three hypotheses through a long-term litter decomposition experiment and found experimental evidence for an interactive influence of both "initial litter quality hypothesis" and "decomposer control hypothesis" on the chemistry of decomposing litter. For example, Strickland et al. (2009b) also demonstrated the complementary action of both the input quality and the decomposer community composition on litter decomposition.

Most past studies addressed the initial $\mathrm{C}$ substrate quality effect by adding isotopically labeled and/or chemically distinct plant litters to soils in laboratory microcosms. Labeling with ${ }^{13} \mathrm{C}$ or ${ }^{14} \mathrm{C}$ isotopes allows separate quantification of SOC-derived $\mathrm{CO}_{2}$ and substrate-derived $\mathrm{CO}_{2}$, and specifically resolves the effects of substrate additions on SOC turnover (Kuzyakov and Cheng, 2001; Leake et al., 2006; Williams et al., 2006; Werth and Kuzyakov, 2008). Isotopically labeled natural plant litter, however, cannot be used to identify the role of specific litter constituents in SOC dynamics (Grayston et al., 1998; Loreau, 2001). One way to overcome this issue is to apply isotopically labeled C compounds representing different constituents of plant residues, e.g., simple sugars, polysaccharides, proteins, lipids, and/or aromatic compounds, to observe their direct effect on SOC decomposition (e.g., Brant et al., 2006; Hoyle et al., 2008; Schneckenberger et al., 2008; Strahm and Harrison, 2008; de Graaff et al., 2010). These studies indicated increased, decreased or no change in SOC decomposition dynamics due to the addition of substrates compared to unamended control treatments, which could be explained by a multitude of factors, including different energy levels and physiological states of microbes, different soil properties and different types and amounts of externally added C (Zhang et al., 2013). In general, accelerated SOC decomposition was observed when simple, dissolved substrates were added to soil, indicating rapid energy conversion from simple $\mathrm{C}$ sources (Blagodatskaya and Kuzyakov, 2008). However, a recent study showed that the amount of added glucose $\mathrm{C}$ remained in soil after 6 months was substantially higher than the amount of SOC loss induced by glucose addition (Qiao et al., 2013). Most of these studies used only labile $\mathrm{C}$ compounds such as simple sugars and organic acids as $\mathrm{C}$ amendments, and did not account for more recalcitrant $\mathrm{C}$ compounds such as lignin, fatty acids, lipids, etc. Therefore, more studies with isotopically labeled substrate additions are needed to determine the role of initial litter quality in SOC decomposition.

In accordance with the decomposer community hypothesis, the magnitude of SOC change depends on the abundance and functional types, e.g., fresh $\mathrm{C}$ decomposers and SOC decomposers, of soil microbial communities (Fontaine et al., 2003). Bacteria and fungi are the major drivers of sub- strate and SOC decomposition comprising more than $90 \%$ of the soil microbial biomass, and clear evidence exists that these groups function differently in the decomposition process (de Graaff et al., 2010). There is a general understanding that easily available simple $\mathrm{C}$ compounds are taken up by the fast-growing $r$-strategists in the early stages of decomposition, while in the later stages, slow-growing k-strategists break down more recalcitrant $\mathrm{C}$, i.e., compounds having higher thermodynamic activation energies (Wardle et al., 2002; Fontaine et al., 2003; Blagodatskaya and Kuzyakov, 2008). Among the r-strategists, bacteria are mostly considered responsible for utilizing labile $\mathrm{C}$ sources immediately after their addition to soils (Paterson et al., 2007; MooreKucera and Dick, 2008). Fungi are commonly regarded as kstrategists utilizing $\mathrm{C}$ from more recalcitrant substrates (Otten et al., 2001). There are many exceptions to this general framework. For example, Fierer et al. (2007) found out that many members of the bacteria that belong to the Acidobacteria phylum exhibit attributes of $\mathrm{k}$-strategists. Nottingham et al. (2009) reported that gram-negative bacteria also belong to k-strategists and are responsible for the decomposition of complex C compounds, and Rinnan and Bååth (2009) did not find evidence that bacteria were more efficient at utilizing simple compounds than fungi. An evaluation of the interplay of these life-history strategies in SOC turnover across a suite of substrates, soils and microbial communities is still lacking, and is essential to resolving the role of the decomposer community in SOC dynamics.

Lab-scale incubation studies have been instrumental to quantify the influence of initial litter quality and decomposer community by modeling SOC pool sizes and mineralization rates. Although laboratory incubations deviate from natural ecosystem environments in terms of continuous $\mathrm{C}$ input, microbial community structure and environmental conditions, they help to isolate specific mechanisms by systematically eliminating variations in certain environmental variables. Since there is no continuous $\mathrm{C}$ input during the course of the experiment, incubation studies can be used to quantify the mineralization kinetics of different fractions of $\mathrm{C}$ pools according to different types of substrate addition (Schädel et al., 2013). Statistical models are used to estimate the sizes and rates of SOC pools by curve fitting. Within these constraints, total SOC is most often divided into three pools with fast, intermediate and slow mineralization rates (Trumbore, 1997; Krull et al., 2003). The terminology, definitions and measurement techniques of these pools, however, vary widely in the literature. The lack of experimental data using multiple substrates in long-term incubation experiments, however, limits the understanding of the role of substrate complexity and the decomposer community (von Lützow and Kögel-Knabner, 2009; Schädel et al., 2013).

In this paper we used long-term incubations to investigate how the chemistry of added $\mathrm{C}$ substrates affected mineralization of the substrate $\mathrm{C}$ and of the SOC, and the composition of the decomposer community in several different soils. 
Table 1. Sampling locations and pre-incubation soil properties.

\begin{tabular}{lcccc}
\hline & \multicolumn{3}{c}{ Soils } \\
\cline { 2 - 5 } Descriptions & Mollisol & Ultisol & Andisol & Gelisol \\
\hline Sampling location & Batavia, & Lavras, Minas & Krýsuvíkurheiði, & Fairbanks, \\
& Illinois, USA & Gerais, Brazil & Reykjanes, Iceland & Alaska, USA \\
Organic C $\left(\mathrm{g} \mathrm{kg}^{-1}\right)$ & $29.8 \pm 0.50$ & $23.2 \pm 1.2$ & $74.5 \pm 0.10$ & $20.5 \pm 0.10$ \\
Total N $\left(\mathrm{g} \mathrm{kg}^{-1}\right)$ & $3.00 \pm 0.02$ & $1.97 \pm 0.08$ & $7.09 \pm 1.08$ & $1.32 \pm 0.02$ \\
Microbial biomass C $\left(\mathrm{mg} \mathrm{kg}^{-1}\right)$ & $640 \pm 35$ & $515 \pm 42$ & $856 \pm 39$ & $48 \pm 2.30$ \\
pH $\left(1 \mathrm{soil} \mathrm{:}_{2} \mathrm{O}\right)$ & $7.64 \pm 0.10$ & $5.42 \pm 0.01$ & $5.84 \pm 0.01$ & $7.03 \pm 0.10$ \\
Silt $\left(\mathrm{g} \mathrm{kg}^{-1}\right)$ & $570 \pm 30$ & $170 \pm 20$ & $570 \pm 46$ & $790 \pm 49$ \\
Clay $\left(\mathrm{g} \mathrm{kg}^{-1}\right)$ & $350 \pm 15$ & $450 \pm 32$ & $120 \pm 08$ & $130 \pm 11$ \\
\hline
\end{tabular}

Values are mean \pm standard error $(n=3)$.

We chose to conduct this study in different soils because soil types impart a major control on soil microbial communities due to the interaction of soil biota with a wide range of physico-chemical soil properties (Schimel and Schaeffer, 2012; Van Horn et al., 2013). Soil pH is a single major variable explaining the differences in soil microbial communities; however, other soil variables, including soil moisture, soil texture, SOC and the $\mathrm{C}: \mathrm{N}$ ratio, also showed correlations with types and diversities of soil microbes (Lauber et al., 2008; Rousk et al., 2010; Lee et al., 2012). We hypothesized that (i) cumulative respiration of substrate $\mathrm{C}$ and native SOC would be higher when soils are amended with simple substrates compared to more complex substrates, because energy will be more readily available to microbes, and that (ii) both incubation time and the relative recalcitrance of the added substrate would favor soil fungi over bacteria. To test these hypotheses, we conducted a 270 day long laboratory incubation experiment using four different soils that spanned a wide range in climate, soil development and type and quantity of organic $\mathrm{C}$ inputs, and these were applied with four different uniformly labeled ${ }^{14} \mathrm{C}$ substrates (monosaccharide, polysaccharide, aromatic, fatty acid). The ${ }^{14} \mathrm{C}$ labeling enabled us to separate substrate-derived $\mathrm{CO}_{2}$ from native SOC-derived $\mathrm{CO}_{2}$. We tested the effect of different substrate additions on substrate and native $\mathrm{C}$ respiration using a first-order exponential decay model, and utilized quantitative polymerase chain reaction (qPCR) to compare bacterial and fungal gene copy numbers.

\section{Materials and methods}

\subsection{Soil sampling and characterization}

Soils were collected from four contrasting climatic zones temperate, tropical, sub-arctic and arctic. The selected soils are from major soil orders of the respective climatic regions: Mollisol (temperate), Ultisol (tropical), Andisol (sub-arctic), and Gelisol (arctic) (Table 1). Multiple soil cores were col- lected randomly from each location to a depth of $15 \mathrm{~cm}$, pooled to form a composite sample per location and sieved to $<2 \mathrm{~mm}$. The Andisol and the Gelisol samples also contained the surface $\mathrm{O}$ horizon. The sieved soils were stored in the refrigerator for a few weeks before the experiment. Subsamples $(n=3)$ of the soils were taken for the determination of organic $\mathrm{C}$, total $\mathrm{N}$, microbial biomass $\mathrm{C}(\mathrm{MBC})$, soil $\mathrm{pH}$, and soil texture (Table 1). Organic $\mathrm{C}$ and total $\mathrm{N}$ concentrations were determined by combustion method using a Leco combustion analyzer (Leco Corp., St. Joseph, MI) (Nelson and Sommers, 1996) after removing the inorganic $\mathrm{C}$ by treating with $3 \mathrm{M} \mathrm{HCl}$ for $1 \mathrm{~h}$. Determination of $\mathrm{MBC}$ was conducted by the chloroform fumigation extraction method by dividing the $\mathrm{C}$ concentration (difference in $\mathrm{C}$ between fumigated and non-fumigated sub-samples) by the extraction efficiency $k$, which is usually estimated as 0.45 (Vance et al., 1987; Beck et al., 1997). Soil $\mathrm{pH}$ was determined by shaking 1 part soil in 2 parts Milli-Q (MQ) water and measuring the $\mathrm{pH}$ of the supernatant (Thomas, 1996), and soil texture was determined by the Bouyoucos hydrometer method (Gee and Or, 2002).

\subsection{Carbon substrates}

Four uniformly labeled ${ }^{14} \mathrm{C}$ substrates were used: glucose, starch, cinnamic acid and stearic acid, representing several dominant $\mathrm{C}$ compounds present in plant litter and SOC, and spanning a range of chemical lability. Glucose is a common simple sugar and starch is a common polysaccharide in plant residues; cinnamic acid contains an aromatic ring and is a common product of lignin depolymerization, and stearic acid represents a fatty acid (Orwin et al., 2006; Rinnan and Bååth, 2009). Similar to Orwin et al. (2006), we selected compounds containing only $\mathrm{C}$, hydrogen, and oxygen, and lacking nutrient elements such as nitrogen and phosphorus. These nutrients are expected to cause confounding effects on microbial activities and $\mathrm{C}$ decomposition (Orwin et al., 2006). Availability in uniformly labeled ${ }^{14} \mathrm{C}$ form $\left(\mathrm{U}_{-}{ }^{14} \mathrm{C}\right)$ was also another criterion for the compound selection. ${ }^{14} \mathrm{C}$ labeled glucose, ${ }^{14} \mathrm{C}$ labeled starch and ${ }^{14} \mathrm{C}$-labeled stearic acid were 
purchased from PerkinElmer and ${ }^{14} \mathrm{C}$-labeled cinnamic acid was purchased from American Radiolabeled Chemicals, Inc.

\subsection{Incubation experiments}

The soils were preincubated for 1 week prior to the start of the experiment at conditions similar to the experiment, i.e., at $20^{\circ} \mathrm{C}$ in the dark in a temperature- and humidity-controlled room. We used 5 control (unamended) replicates of each of 4 soils for measuring native SOC respiration. Two replicates were destructively harvested at days 4 and 30 and stored at $-20^{\circ} \mathrm{C}$ for microbial community analysis. The three remaining replicates were monitored for respiration until they were destructively harvested for community analysis at 270 days. An identical scheme was used for the soils amended with the 4 different substrates to measure ${ }^{14} \mathrm{CO}_{2}$ evolved from decomposition of substrate and $\mathrm{CO}_{2}$ evolved from native SOC. Our initial experiment thus had 4 soils, each having 5 controls and five ${ }^{14} \mathrm{C}$ substrate additions, using 4 different substrates. Though we could include only one replicate for the destructive sampling at day 4 and day 30 due to limitations of space, soil, and ${ }^{14} \mathrm{C}$ substrate, we conducted three analytical replicates of the microbial community measurements for these sampling times, and three experimental replicates for the 270-day sampling time.

For the substrate addition experiments, $25 \mathrm{~g}$ (oven-dry basis) soils were amended with $0.4 \mathrm{mg} \mathrm{Cg}^{-1}$ soil substrates, which were labeled with 296 Becquerel $\mathrm{g}^{-1}$ soil $\mathrm{U}_{-}{ }^{14} \mathrm{C}$ substrate. The substrates were added in dissolved form and mixed well with the soil using a spatula. The $25 \mathrm{~g}$ control soils were mixed well with equal volume of MQ water. The final moisture content of substrate-amended and unamended samples was maintained at $50 \%$ WHC with MQ water. The solvents were MQ water for glucose and starch, ethanol for cinnamic acid and toluene for stearic acid. Organic solvents were used for cinnamic acid and stearic acid because these compounds are sparingly soluble in water. We introduced only a small amount of organic solvents to the samples $(4 \mu \mathrm{L}$ ethanol $\mathrm{g}^{-1}$ soil and $6 \mu \mathrm{L}$ toluene $\mathrm{g}^{-1}$ soil) and our preliminary experiments revealed that the solvents did not influence the microbial activities (Supplement Fig. S1). Since results across soils were similar, data from only one soil (Andisol) were presented in Supplement Fig. S1.

\subsection{Measurement of $\mathrm{CO}_{2}$ respiration}

Specimen cups containing the substrate-amended and unamended control soils were placed in $1 \mathrm{~L}$ wide-mouthed glass jars, along with a glass vial containing $17 \mathrm{~mL}$ of $0.5 \mathrm{~N} \mathrm{NaOH}$ solution to trap the evolved $\mathrm{CO}_{2}$. The jars were closed tightly and incubated in the dark at $20^{\circ} \mathrm{C}$ for up to 270 days in a temperature- and humidity-controlled room. The $\mathrm{NaOH}$ solution was exchanged 15 times during the experiment at daily to weekly intervals in the first two months, and at monthly intervals thereafter. The jars were sufficiently ventilated each time when they were opened for $\mathrm{NaOH}$ solution exchange in order to avoid anaerobic conditions inside the jar. There is a possibility of $\mathrm{CO}_{2}$ escaping from open jars, so care was taken to close the jar soon after sufficient ventilation. Blank correction for the amount of $\mathrm{CO}_{2}$ trapped inside the jar was done by collecting $\mathrm{NaOH}$ traps from triplicate, non-soil-containing jars at all the time points.

The amount of total $\mathrm{C}$ respiration is defined as the sum of SOC-derived $\mathrm{CO}_{2}$ and substrate-derived ${ }^{14} \mathrm{CO}_{2}$, where the control (unamended) samples have no contribution from substrate. The total mineralized $\mathrm{CO}_{2}$ was determined by titrating an aliquot of $\mathrm{NaOH}$ solution collected at each sampling time with $0.5 \mathrm{~N} \mathrm{HCl}$ by an automatic titrator (Metrohm USA). Before the titration, the $\mathrm{CO}_{2}$ collected in $\mathrm{NaOH}$ solution was precipitated as barium carbonate $\left(\mathrm{BaCO}_{3}\right)$ by adding $2 \mathrm{~mL}$ $10 \%$ barium chloride $\left(\mathrm{BaCl}_{2}\right)$. The volume of acid needed to neutralize the remaining $\mathrm{NaOH}$ (unreacted with $\mathrm{CO}_{2}$ ) was determined by the titration, which was used to calculate the concentration of $\mathrm{CO}_{2}$ trapped in the $\mathrm{NaOH}$ solution ( $\mathrm{Zi}-$ bilske, 1994). The evolution of substrate $\mathrm{C}$ was determined by measuring the activity of ${ }^{14} \mathrm{CO}_{2}$ trapped in a $\mathrm{NaOH}$ solution collected from the substrate-amended samples with a Packard Tri-Carb Liquid Scintillation Counter (LSC) after mixing $5 \mathrm{~mL}$ of the $\mathrm{NaOH}$ solution with $10 \mathrm{~mL}$ of the Ultima Gold XR (PerkinElmer) scintillation cocktail. The $\mathrm{CO}_{2}$ derived from SOC for the substrate-amended samples was calculated by subtracting substrate-derived ${ }^{14} \mathrm{CO}_{2}$ from the total $\mathrm{CO}_{2}$.

\subsection{Microbial gene copy numbers}

Microbial DNA extraction was conducted with $0.25 \mathrm{~g}$ of moist soil using the PowerSoil DNA Isolation Kit (MOBIO Laboratories, Inc., CA, USA). The abundance of the ribosomal RNA (rRNA) genes was determined by quantitative real time polymerase chain reaction (qPCR) on a CFX96TM Real-Time PCR Detection System (Bio-Rad Laboratories, CA, USA) with group specific ribosomal DNA gene primers using iQ SYBR Green Supermix (Bio-Rad, CA, USA). A small segment of the sample DNA was amplified using primer pairs that targeted the conserved region of the rRNA. Gene copy numbers for bacteria and fungi were determined in analytical triplicates using standard curves constructed from group specific microorganisms and were expressed in dry weight basis. The primers, PCR reaction conditions, composition of the reaction mixture and the pure cultures used for preparing the standard curves are described in Supplement Table S1. Though qPCR is a rapid method to quantify microbial gene copy numbers, it is associated with several caveats including over or underestimation of fungal abundance due to many or no nuclei in fungal cells, difference in DNA efficiencies and gene amplifications across microbial taxa, and the presence of multiple copies of the same gene within a single individual (Rousk et al., 2010; Strickland and Rousk, 2010). 


\subsection{Exponential decay modeling}

The respiration data (both the substrate $\mathrm{C}$ and SOC) were tested using a double and a triple pool first-order exponential decay model (Farrar et al., 2012):

Double pool model: $\mathrm{C}_{\mathrm{t}}=\mathrm{C}_{1}\left(e^{-k_{1} t}\right)+\mathrm{C}_{2}\left(e^{-k_{2} t}\right)$

Triple pool model: $\mathrm{C}_{\mathrm{t}}=\mathrm{C}_{1}\left(e^{-k_{1} t}\right)$

$+\mathrm{C}_{2}\left(e^{-k_{2} t}\right)+\mathrm{C}_{3}\left(e^{-k_{3} t}\right)$

where $\mathrm{C}_{\mathrm{t}}$ is the total substrate $\mathrm{C}$ (in terms of $\%$ of added substrate $\mathrm{C}$ ) or total SOC (in terms of \% of initial SOC) remaining in time $t, \mathrm{C}_{1}, \mathrm{C}_{2}$, and $\mathrm{C}_{3}$ are pool sizes, and $k_{1}, k_{2}$ and $k_{3}$ are associated mineralization rates. For the double pool model, $\mathrm{C}_{1}$ and $\mathrm{C}_{2}$ are defined as fast and slow pools, respectively, and for triple pool model, $\mathrm{C}_{1}, \mathrm{C}_{2}$ and $\mathrm{C}_{3}$ are defined as fast, intermediate and slow pools, respectively. For each set of data, multiple pool models were fit using Sigma plot v11 (Systat Software Inc., IL, USA), and dependency values and $r^{2}$ for fit parameters were calculated. We followed two criteria to determine the best fits as outlined in Farrar et al. (2012): (i) dependencies less than 0.98 , and (ii) a statistically greater $r^{2}$ over a lower-order fit.

\subsection{Statistical analysis}

Statistical analyses were conducted using SAS software (SAS Institute Inc., 2002). The effect of substrate type on substrate-derived and SOC-derived respiration was determined by repeated measures analysis using the PROC MIXED option of SAS with incubation length considered as the repeated measure with autoregressive 1 covariance structure. The repeated measures analysis with the PROC MIXED option of SAS is analogous to the generalized linear model analysis with the PROC GLM option of SAS, except that the former allows modeling of the covariance structure of the data set to account for unevenly spaced sampling dates (Littel et al., 1996; Schaeffer et al., 2007). Post hoc comparisons for determining the effect of substrate types on respiration, and modeled mineralization parameters (pool sizes and rates) in each soil were performed using PROC GLM of SAS. The treatment effects were separated using Fisher's protected least significant difference (LSD) test. A $t$ test was performed to determine if the fungal-to-bacterial $(\mathrm{F}: \mathrm{B})$ gene copy ratio upon substrate addition was significantly different from the $\mathrm{F}: \mathrm{B}$ ratio of unamended controls at each time point. In all statistical tests, the mean differences were considered significant at $P \leq 0.05$. Error bars are represented as one standard error of the mean based on analytical replicates at day 4 and day 30 , and experimental replicates at day 270 .

\section{Results}

\subsection{Substrate-derived $\mathrm{C}$ respiration}

There was a significant effect of substrate chemistry on substrate mineralization $(P \leq 0.05)$, with respiration from glucose addition being the greatest (Fig. 1). Respiration rate was highly variable among substrates in the first several days of incubation. After day 2 of incubation, the proportion of added $\mathrm{C}$ respired as ${ }^{14} \mathrm{CO}_{2}$ for different soils was 18 to $28 \%$ from glucose, 12 to $16 \%$ from starch, 0.2 to $5 \%$ from cinnamic acid and 0.1 to $0.4 \%$ from stearic acid. Thus, a considerable initial delay was observed in the mineralization of ${ }^{14} \mathrm{C}$ from cinnamic acid and stearic acid as compared to glucose and starch. At the end of incubation, cumulative respiration for different soils was 52 to $60 \%$ of added ${ }^{14} \mathrm{C}$ for glucose, 39 to $49 \%$ for starch, 33 to $53 \%$ for cinnamic acid and 43 to $57 \%$ for stearic acid. Respiration from substrates varied within a narrow range for the Mollisol and the Andisol throughout the course of incubation compared to the Ultisol and the Gelisol. At the end of incubation, the proportion of substrate ${ }^{14} \mathrm{C}$ respired for all substrates combined was 41 to $50 \%$ for the Mollisol, 43 to $54 \%$ for the Andisol, 33 to $57 \%$ for the Ultisol and 39 to $60 \%$ for the Gelisol.

\subsection{SOC-derived $\mathrm{C}$ respiration}

The SOC-derived C respiration was not significantly affected by the substrate addition in the first several weeks of incubation; however, the cumulative amount of SOC respired at the end of incubation changed as a function of substrate type (Fig. 2, Supplement Table S2). The cumulative amount of native SOC mineralized from unamended soils varied from 2.4 to $4.1 \mathrm{~m} \mathrm{C} \mathrm{g}^{-1}$ across the soils (Supplement Table S2). Adding substrates significantly affected the cumulative amount of native SOC mineralized from the Ultisol, the Andisol and the Gelisol, but not from the Mollisol (Fig. 2, Supplement Table S2). Contrary to our hypothesis, cinnamic acid and stearic acid additions resulted in mineralization of more native SOC than from unamended control in all soils except the Mollisol. Compared to the unamended control, cinnamic acid treatment caused $24 \%$ more mineralization of native SOC in the Ultisol, $36 \%$ more in the Andisol, and $20 \%$ more in the Gelisol. Likewise, stearic acid addition caused $28 \%$ more SOC mineralization in the Ultisol and the Andisol, and $30 \%$ more in the Gelisol. Cumulative SOC mineralization from glucose and starch treated soils was statistically similar to unamended soils (Supplement Table S2).

\subsection{Microbial community composition}

The fungal-to-bacterial $(\mathrm{F}: \mathrm{B})$ ratios were calculated from the fungal and bacterial gene copy numbers measured by qPCR (Supplement Figs. S2 and S3). To compare the F : B ratios from the substrate-amended and unamended samples, we calculated the difference $\left(F: B_{\text {amended }}-F: B_{\text {unamended }}\right)$ at each 

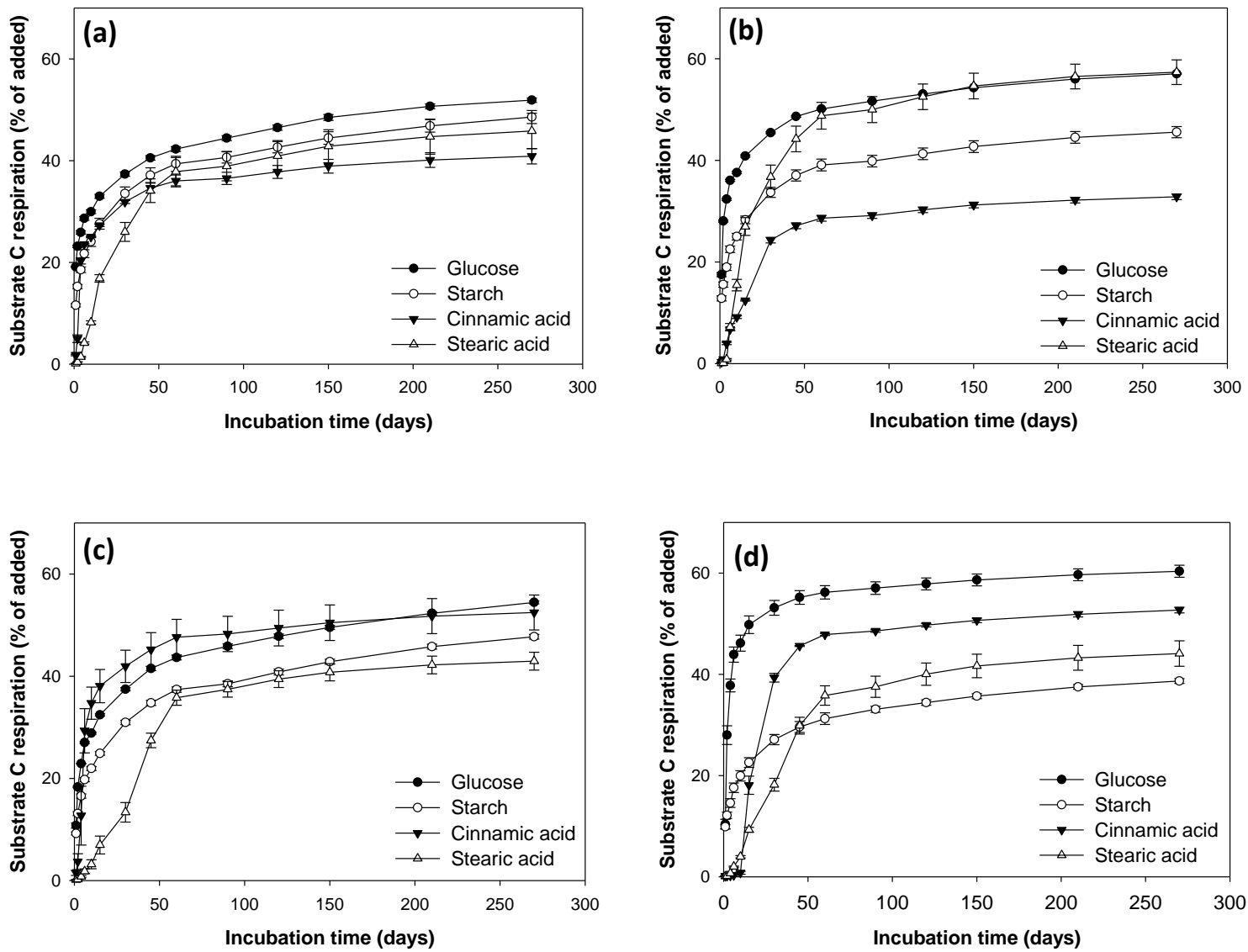

Figure 1. Substrate C respiration in response to the addition of four substrates in Mollisol (a), Ultisol (b), Andisol (c), and Gelisol (d). Symbols represent proportion of added substrate $\mathrm{C}$ respired at each sampling time along with standard error bar $(n=3)$.

sampling point (days 4, 30 and 270) (Fig. 3). Positive values indicate greater fungal (and lesser bacterial) numbers in amended vs. unamended soils, and negative values indicate smaller fungal (and greater bacterial) numbers in amended vs. unamended soils. We report any relative change in $\mathrm{F}: \mathrm{B}$ ratio due to substrate addition in relation to unamended soils. Positive values were nearly always observed for the Ultisol, the Andisol, and the Gelisol, and these values became more positive over time, indicating an increasing fungal presence in amended vs. unamended soils. At day 4, the difference between the $\mathrm{F}: \mathrm{B}$ ratios between substrate-amended and unamended soils was small, except for glucose addition to the Mollisol and the Ultisol, which showed relatively more fungal gene copy numbers. By day 270, cinnamic acid and stearic acid additions enhanced the fungal population compared to the unamended control for all soils except the Mollisol.

\subsection{Pools and rates associated with respiration}

Native SOC respiration was best modeled by the double pool exponential decay model. Irrespective of the substrate treatments, the lowest proportion of the initial SOC was assigned to the fast pool (Pool 1) for the Andisol compared to other soils (Fig. 4a). The size of Pool 1 was mostly greater for soils amended with stearic acid and cinnamic acid than for control soils and soils amended with other substrates. For the Gelisol and the Ultisol, cinnamic acid and stearic acid additions yielded a lower mineralization rate $k_{1}$ associated with Pool 1, while no difference was observed for the Mollisol or the Andisol (Fig. 4b). The mineralization rate $k_{2}$ corresponding to the slow pool (Pool 2) was statistically similar among the substrates for all soils; however, there was a notable decrease in $k_{2}$ for the Andisol in comparison with the other soils (Fig. 4c).

Modeling of substrate-derived respiration data was strongly dependent on substrate chemistry: a triple pool exponential decay model was the best fit for the substratederived ${ }^{14} \mathrm{C}$ respiration following glucose and starch amendments, whereas a double pool model was the best fit following cinnamic acid and stearic acid amendments (Fig. 5). When comparing modeled $\mathrm{C}$ pools from cinnamic/stearic acid to glucose/starch amendments, the size of the fast pool in cinnamic/stearic acid-amended soils was usually greater than the size of the fast pool for glucose and starch amendments (Fig. 5a). However, the mineralization rate associated 

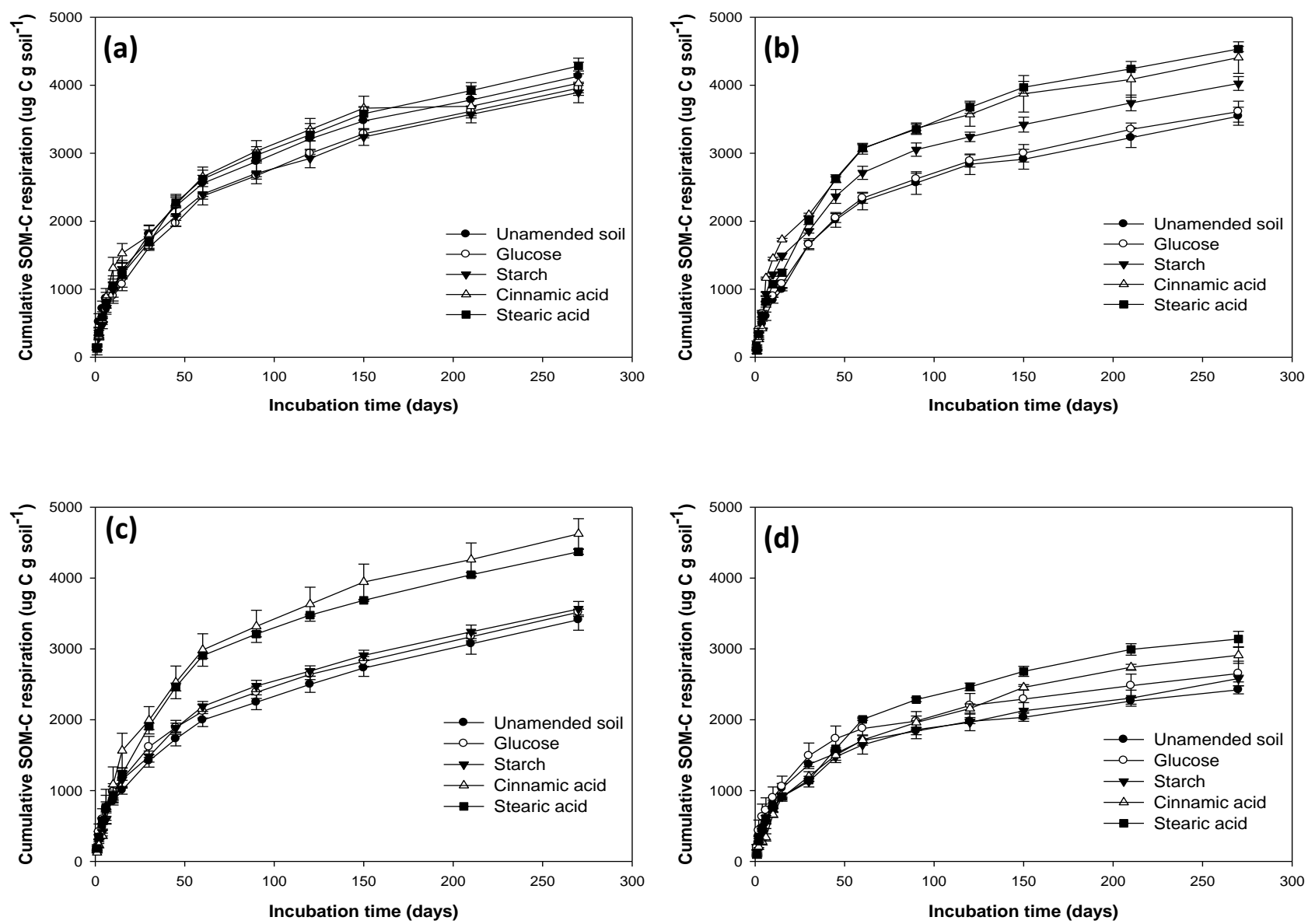

Figure 2. Soil organic carbon respiration in response to the addition of four C substrates in Mollisol (a), Ultisol (b), Andisol (c), and Gelisol (d). Symbols represent cumulative soil organic carbon respired as $\mathrm{CO}_{2}$ in each sampling time along with standard error bar $(n=3)$.

with the fast pool showed a reverse trend (Fig. 5b), with rates corresponding to glucose and starch amendments being one or two orders of magnitude greater than the rates corresponding to cinnamic and stearic acid amendments. The mineralization rate associated with the slow pool was considerably lower for cinnamic and stearic acid when they were applied to the Andisol and the Gelisol (Fig. 5d), compared to the Ultisol and the Mollisol. A third intermediate pool was invoked for glucose and starch respiration data, and greater intermediate pool sizes and mineralization rates were observed with starch additions than with glucose additions for all soils (Fig. 5e, f). The inverse relationship observed between pool sizes and mineralization rates of the fast pool was not observed for either the intermediate or the slow pools.

\section{Discussion}

\subsection{Substrate-derived $\mathrm{C}$ respiration}

In accordance with our hypothesis, substrate ${ }^{14} \mathrm{C}$ mineralization rate and extent were influenced by the initial substrate quality (Fig. 1). Indeed, the greatest mineralization of substrate ${ }^{14} \mathrm{C}$ occurred following glucose addition (52 to $60 \%$ of added ${ }^{14} \mathrm{C}$ ); and in the initial days after substrate addition, we observed more rapid mineralization of ${ }^{14} \mathrm{C}$ from glucose and starch than from cinnamic acid and stearic acid (Fig. 1). Our results with glucose and starch was quantitatively similar to previous studies (Bremer and Kuikman, 1997; Jones and Murphy, 2007; Hoyle et al., 2008) and in a similar experiment, Orwin et al. (2006) found that $\mathrm{CO}_{2}$ respiration from sugars was greater than respiration from fatty acids and tannin. A considerably higher $\mathrm{CO}_{2}$ efflux in the first three days of incubation was found when a synthetic root exudate cocktail containing $60 \%$ sugars, $35 \%$ organic acids and $2 \%$ amino acids was added to soils (de Graaff et al., 2010). The slower degradation following starch addition in comparison to glucose addition in our study could be due to the requirement of extracellular enzymes ( $\alpha$-glucosidase) for starch hydrolysis to occur (Kelley et al., 2011; German et al., 2012), while glucose can be directly assimilated by microbes.

Contrary to the general notion that the fast-growing sugar feeders, i.e., r-strategists, are composed mostly of bacterial 

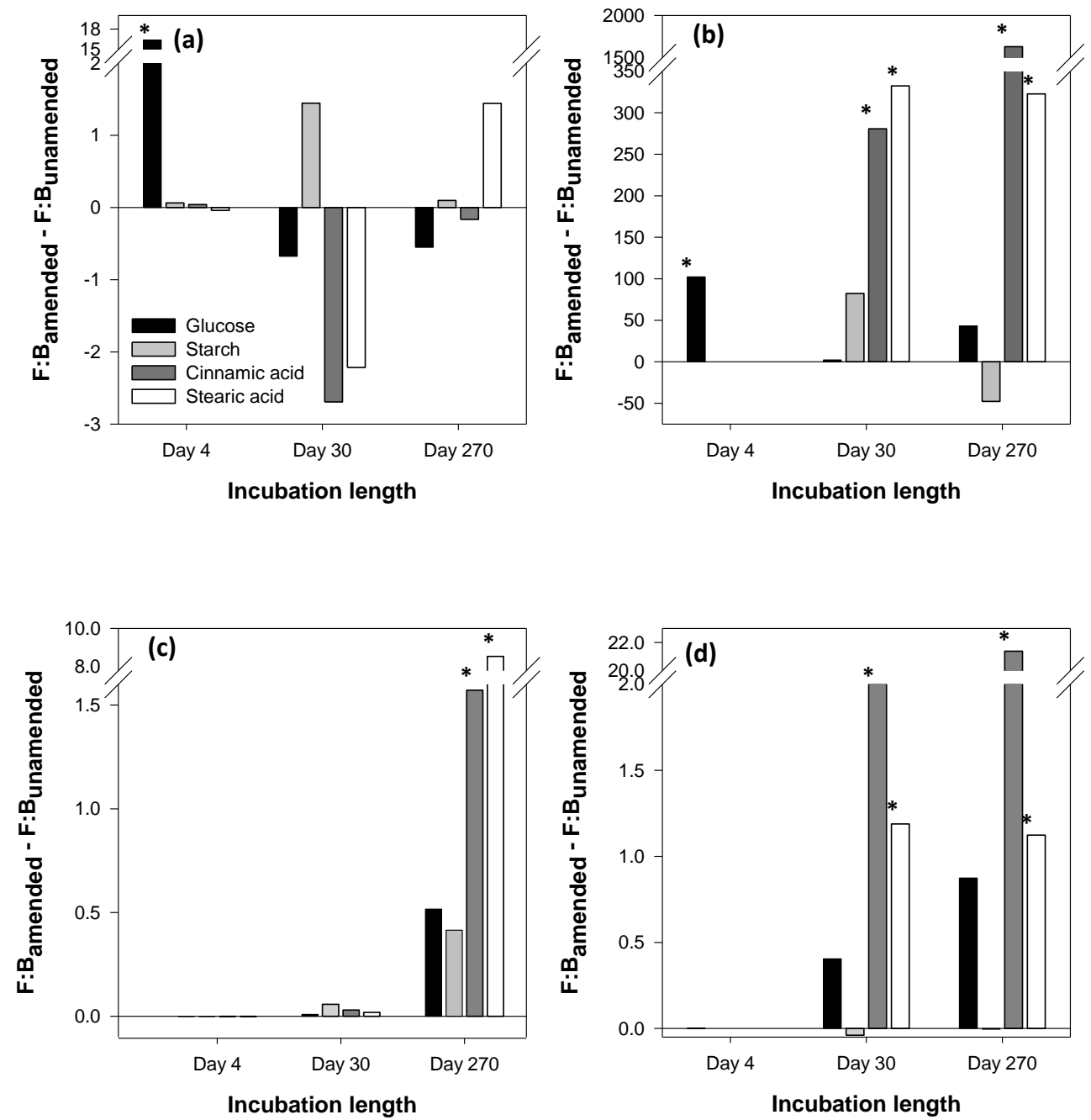

Figure 3. The difference in the fungal-to-bacterial gene copy ratios between amended and unamended treatments $\left(\mathrm{F}: \mathrm{B}_{\text {amended }}{ }^{-}\right.$ $\left.\mathrm{F}: \mathrm{B}_{\text {unamened }}\right)$ in response to the addition of four substrates in Mollisol (a), Ultisol (b), Andisol (c), and Gelisol (d). ${ }^{*}$ indicates that $\mathrm{F}: \mathrm{B}_{\text {amended }}-\mathrm{F}: \mathrm{B}_{\text {unamended }}$ is significantly different from zero.

species (Paterson et al., 2007; Moore-Kucera and Dick, 2008), we observed enhanced $F: B$ values due to increased fungal gene copy numbers at day 4 following glucose addition, indicating that some fungi responded quickly to substrate addition (Fig. 3, Supplement Fig. S2) (Broeckling et al., 2008; Chiginevaa et al., 2009; de Graaff et al., 2010). Panikov (1995) and Rinnan and Bååth (2009) also observed fungal-controlled mineralization of glucose in the initial phase of similar microcosm studies. Addition of a synthetic root exudate mixture containing $60 \%$ simple sugars resulted in a higher proportion of fungal growth relative to bacterial growth at day 3 (de Graaff et al., 2010).

Sugars and other easily assimilable substrates added to soil are used by microbes not only for the production of energy and release of $\mathrm{CO}_{2}$, but also for the biosynthesis of products including extracellular enzymes, extracellular polysaccharides, cell wall polymers, storage compounds and stress response compounds (Nguyen and Guckert, 2001; Dijkstra et al., 2011; Schimel and Schaeffer, 2012). The proportion of $\mathrm{C}$ initially allocated for biosynthetic processes may take more time to mineralize to $\mathrm{CO}_{2}$. Consequently, we observed continued evolution of ${ }^{14} \mathrm{CO}_{2}$ even after several months of incubation from all the added substrates (including the most labile glucose), albeit at a slower rate. It is therefore very likely that part of the added sugars may have been used as biosynthetic precursors and that those microbial byproducts contributed to the evolution of ${ }^{14} \mathrm{CO}_{2}$ during the later stages of incubation. Qiao et al. (2013) found that 41 to $75 \%$ of added glucose $\mathrm{C}$ remained in soil after 6 months of incubation.

Along with other environmental and soil physico-chemical factors, microbial community structure could also influence the metabolism of $\mathrm{C}$ substrates in soil and the relative access by different groups of microbes (Schimel and Schaeffer, 

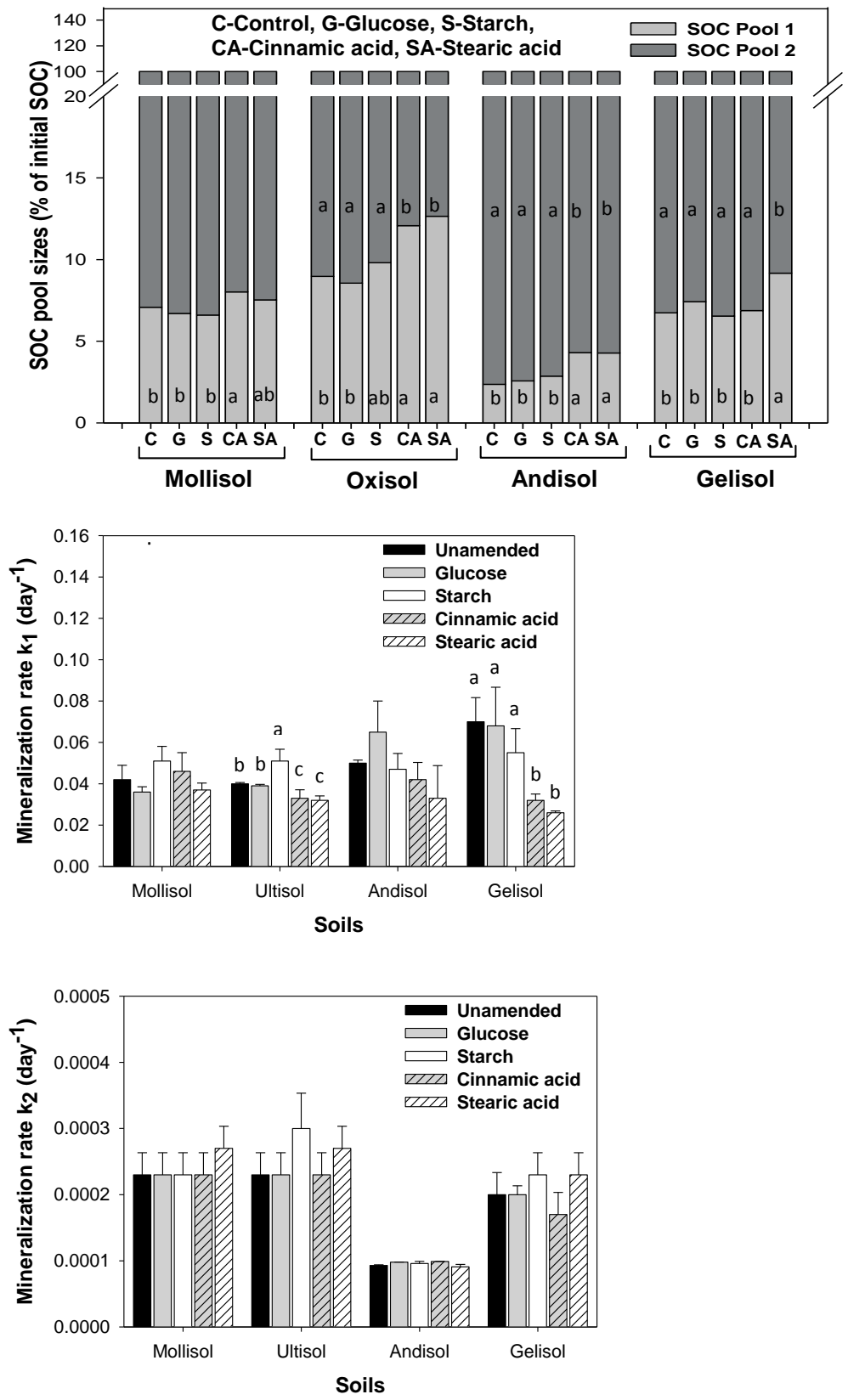

Figure 4. Effect of substrate types on native soil organic carbon mineralization parameters: pool sizes (a), mineralization rate $k_{1}$ associated with Pool 1 (b), and mineralization rate $k_{2}$ associated with Pool 2 (c). Lower-case letters on bar segments in (a) and on top of bars in (b) represent statistical significance at $P<0.05$. No letters mean statistical insignificance.

2012). We observed that mineralization of ${ }^{14} \mathrm{C}$ from cinnamic acid and stearic acid was delayed for several days (Fig. 1). However, this delay was not due to the decreased microbial activity because native SOC mineralization was similar to control. Cinnamic acid and stearic acid are more complex C compounds and expected greater resistance to decomposition compared to glucose and starch because of their higher hydrophobicity, aromatic structure of cinnamic acid, and strong mineral sorption capacity of stearic acid (Orwin et al., 2006; Jagadamma et al., 2014). Specialized microorganisms might be responsible for the mineralization of these relatively complex compounds, and these organisms were either low in abundance in the beginning of the experiment, or the organisms simply took more time to consume and cycle these compounds. Degradation requires the production of specific extra-cellular enzymes before they can be utilized (German et al., 2011). 

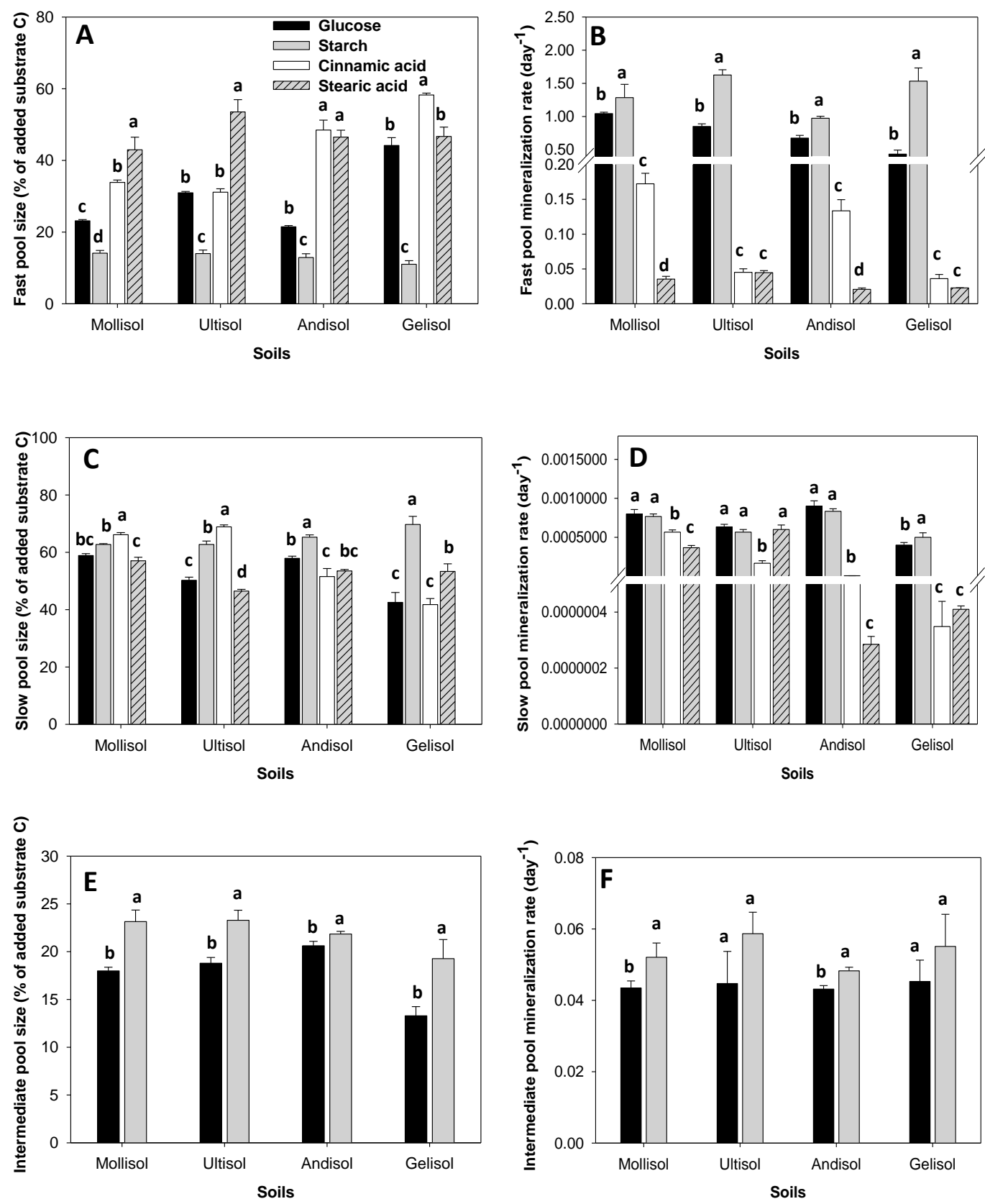

Figure 5. Effect of substrate types on substrate $C$ mineralization parameters: size of fast pool (a), mineralization rate of fast pool (b), size of slow pool (c), mineralization rate of slow pool (d), size of intermediate pool (e) and mineralization rate of intermediate pool (f). Pool sizes of ${ }^{14} \mathrm{C}$ glucose and ${ }^{14} \mathrm{C}$ starch respiration (fast, intermediate and slow pools) and their associated mineralization rates $\left(k_{1}, k_{2}\right.$ and $\left.k_{3}\right)$ were best modeled by a triple pool model, and pool sizes of ${ }^{14} \mathrm{C}$ cinnamic acid and ${ }^{14} \mathrm{C}$ stearic acid respiration (fast and slow pools) and their associated mineralization rates $\left(k_{1}\right.$ and $\left.k_{2}\right)$ were best modeled by a double pool model. Lower-case letters on top of bars represent statistical significance at $P<0.05$.

\subsection{SOC-derived C respiration}

We expected that cumulative respiration of native SOC would be lower when soils are amended with more complex cinnamic acid and stearic acid compared to simpler glucose and starch. Although we found a connection between the chemical composition of substrates added to soils and the stability of native SOC, the results were different than what we originally hypothesized. Surprisingly, cumulative native SOC mineralization was greater with cinnamic acid and stearic acid additions (positive priming) relative to glucose and starch additions and unamended soils that did not cause 
positive priming (Supplement Table S2). Furthermore, the increase in decomposition only became evident after several weeks of incubation (Fig. 2). Past studies that used sugars, organic acids and amino acids to understand the priming processes in soil reported either positive, negative, or no priming effects (Kuzyakov et al., 2007; Hamer and Marschner, 2005; Kuzyakov and Bol, 2006; Blagodatskaya et al., 2007; De Nobili et al., 2001). Hamer and Marschner (2005) added four diverse compounds (fructose, alanine, oxalic acid and catechol) to three different soils, and found that both fructose and alanine always caused positive priming, and that catechol and oxalic acid caused positive and negative priming, depending on the soil type. The priming effect is generally believed to result from increased microbial activity when easily available substrates are added to soils. However, some studies found little or no priming of SOC when simple compounds such as glucose or fructose were added, while some studies observed priming only when more highly polymerized compounds such as plant litter or cellulose were added (Dalenberg and Jager, 1989; Wu et al., 1993). Brant et al. (2006) found positive priming from a forest soil in Oregon following the addition of glucose, glutamate, oxalate and phenol, but the extent of priming was greater with oxalate and phenol addition than with glucose and glutamate addition. Thus the causes and mechanisms of priming are more complex and closely linked to substrate types, soil characteristics, and/or microbial functions. Detailed overview of the processes and mechanisms of priming are described by Blagodatskaya and Kuzyakov (2008).

We also found that cinnamic acid and stearic acid additions were associated with higher $\mathrm{F}$ : $\mathrm{B}$ gene copy ratios during the final stages of incubation relative to other substrates (Fig. 3). It could be possible that the addition of cinnamic acid and stearic acid might have activated some specialized, but slowgrowing fungal populations capable of decomposing more recalcitrant components of SOC at the later stages of incubation. It could also be due to the differences in microbial use efficiency as a function of substrate type (Frey et al., 2013). The processes and mechanisms governing response to different substrates clearly warrant further investigation. Overall, our study reveals that both initial substrate quality and decomposer community are tightly linked and interactively influence the decomposition of both substrate and soil C.

\subsection{Pools of carbon and rates of decomposition}

Carbon pool sizes and mineralization rates from incubation data are used to parameterize ecosystem models. The cumulative $\mathrm{CO}_{2}$ respiration following substrate addition can be described using a double or triple pool first-order exponential decay model, for both amended and unamended soils (Chen et al., 2009; Farrar et al., 2012). In the case of ${ }^{14} \mathrm{C}$ glucose and ${ }^{14} \mathrm{C}$ starch respiration data, both double and triple pool models met our first criteria for fitting, i.e., dependencies less than 0.98 ; however, $r^{2}$ was statistically higher for the triple pool model than for the double pool model. In the case of ${ }^{14} \mathrm{C}$ cinnamic acid, ${ }^{14} \mathrm{C}$ stearic acid and native SOC respiration data, the triple pool model did not meet our first fitting criteria. Consequently, ${ }^{14} \mathrm{C}$ glucose and ${ }^{14} \mathrm{C}$ starch respiration were fitted using a triple pool model, i.e., fast, intermediate and slow pools, and ${ }^{14} \mathrm{C}$ cinnamic acid and ${ }^{14} \mathrm{C}$ stearic acid respiration were fitted using a double pool model, i.e., fast and slow pools (Fig. 5). Farrar et al. (2012) also reported that a triple pool model was the best fit for glucose-derived $\mathrm{CO}_{2}$. The need for two types of models for sugars vs. complex compounds indicates that the initial substrate quality hypothesis hold true for the decomposition of $\mathrm{C}$ input (Wickings et al., 2012); i.e., the chemistry of substrates at the start of the decomposition process strongly influences the mineralization kinetics. The native SOC-derived $\mathrm{CO}_{2}$ data were best modeled using a double pool model, regardless of the type of substrate addition (Fig. 4). The length of incubation experiment could be a determinant for the lack of effect of substrate type on native $\mathrm{C}$ pool partitioning because incubation length reflects the contribution of more recalcitrant pools in the total $\mathrm{CO}_{2}$ efflux (Schädel et al., 2013). Shorter-term incubation data are often dominated by the $\mathrm{CO}_{2}$ from more labile $\mathrm{C}$ compounds. Using 385 days of decomposition data, Schädel et al. (2013) did not find any improvement in the fit for SOC decomposition data when a three pool model was used over a two pool model. Scharnagl et al. (2010) reported that decomposition data from a 900-day incubation experiment were sufficient in constraining all five $\mathrm{C}$ pools in the RothC model. In our study, within 270 days, only 5 to $20 \%$ of initial SOC was lost across all soils and substrate addition treatments (Supplement Table S2), and it suggested that 270-day incubation was not long enough to constrain parameters for the third SOC pool. This differs from our substrate $\mathrm{C}$ mineralization parameters in which three pools were modeled for glucose and starch but only two pools for cinnamic acid and stearic acid. These findings suggest that mineralizable $\mathrm{C}$ inputs can easily be satisfactorily modeled using respiration data from incubation over several months; however, multi-year experiments are needed to constrain more stable components of SOC and more complex carbon additions. This suggests that substrate-specific mineralization kinetics are needed to refine the decomposition rates and pools in $\mathrm{C}$ cycle models.

\section{Conclusions}

This study reveals that substrate quality imparts considerable control on microbial decomposition of substrates and native SOC, and the extent of priming. Our findings also support multiple year incubation experiments to capture the dynamics of more $\mathrm{C}$ pools with distinct mineralization rates. We found that even though complex substrates (cinnamic acid and stearic acid) showed an initial delay in respiration compared to simpler substrates (glucose and starch), complex 
substrates caused positive priming at later stages of incubation with a concomitant increase in fungal abundance. However, the length of incubation was not long enough to model the third pool of more complex substrates (cinnamic acid and stearic acid) and native SOC. Characterizing the dynamics of multiple $\mathrm{C}$ pools is critical, as anthropogenically induced changes in atmospheric $\mathrm{CO}_{2}$ concentration and $\mathrm{N}$ deposition are predicted to alter the quality of both above ground and below ground $\mathrm{C}$ input to soils. Thus, understanding the control of substrate chemistry or quality on soil microbial composition and function will be useful for predicting the future impact of climate change on SOC dynamics.

\section{The Supplement related to this article is available online at doi:10.5194/bg-11-4665-2014-supplement.}

Acknowledgements. This research was funded in part by the Laboratory Directed Research and Development (LDRD) program of the Oak Ridge National Laboratory (ORNL), and by the US Department of Energy Biological and Environmental Research Terrestrial Ecosystem Sciences program. ORNL is managed by UT-Battelle, LLC, for the US Department of Energy under contract DE-AC05-00OR22725. We thank Stan Wullschleger, Anna Wagner, Julie Jastrow, Yuri Zinn and Guðrún Gísladóttir for providing soil samples, and Chad Covert, Jana Phillips and Jennifer Dabbs for help with laboratory analyses. Collection and processing of soil samples from Brazil was supported by CNPq. We also thank two anonymous reviewers for their constructive comments.

Edited by: R. Bol

\section{References}

Angers, D. A. and Mehuys, G. R.: Barley and alfalfa cropping effects on carbohydrate contents of a clay soil and its size fractions, Soil Biol. Biochem., 22, 285-288, 1990.

Beck, T., Joergensen, R. G., Kandeler, E., Makeschin, F., Nuss, E., Oberholzer, H. R., and Scheu, S.: An inter-laboratory comparison of ten different ways of measuring soil microbial biomass C, Soil Biol. Biochem., 29, 1023-1032, 1997.

Berg, B. and McClaugherty, C.: Plant Litter: Decomposition, Humus Formation, Carbon Sequestration, 2nd Edn., SpringerVerlag, Berlin, p. 338, 2008.

Blagodatskaya, E. and Kuzyakov, Y.: Mechanisms of real and apparent priming effects and their dependence on soil microbial biomass and community structure: critical review, Biol. Fertil. Soils, 45, 115-131, 2008.

Blagodatskaya, E. V., Blagodatsky, S. A., Anderson, T.-H., and Kuzyakov, Y.: Priming effects in Chernozem induced by glucose and $\mathrm{N}$ in relation to microbial growth strategies, Applied Soil Ecol., 37, 95-105, 2007.

Brant, J. B., Sulzman, E. W., and Myrold, D. D.: Microbial community utilization of added carbon substrates in response to longterm carbon input manipulation, Soil Biol. Biochem., 38, 22192232, 2006.
Bremer, E. and Kuikman, P.: Microbial utilization of ${ }^{14} \mathrm{C}-\mathrm{U}$ glucose in soil is affected by the amount and timing of glucose additions, Soil Biol. Biochem., 26, 511-517, 1994.

Broeckling, C. D., Broz, A. K., Bergelson, J., Manter, D. K., and Vivanco, J. M.: Root exudates regulate soil fungal community composition and diversity, Appl. Environ. Microbiol., 74, 738744, 2008.

Chen, H., Fan, M., Billen, N., Stahr, K., and Kuzyakov, Y.: Effect of land use types on decomposition of ${ }^{14} \mathrm{C}$-labelled maize residue (Zea mays L.), Eur. J. Soil Biol., 45, 123-130, 2009.

Chiginevaa, N. I., Aleksandrovab, A. V., and Tiunovc, A. V.: The addition of labile carbon alters residue fungal communities and decreases residue decomposition rates, Appl. Soil Ecol., 42, 264270, 2009.

Dalenberg, J. W. and Jager, G.: Priming effect of some organic additions to ${ }^{14} \mathrm{C}$-labelled soil, Soil Biol. Biochem., 21, 443-448, 1989.

de Graaff, M.-A., Classen, A. T., Castro, H. F., and Schadt, C.W.: Labile soil carbon inputs mediate the soil microbial community composition and plant residue decomposition rates, New Phytol., 188, 1055-1064, 2010.

De Nobili, M., Contin, M., Mondini, C., and Brookes, P. C.: Soil microbial biomass is triggered into activity by trace amounts of substrate, Soil Biol. Biochem., 33, 1163-1171, 2001.

Dijkstra, P., Dalder, J. J., Selmants, P. C., Hart, S. C., Koch, G. W., Schwartz, E., and Hungate, B. A.: Modeling soil metabolic processes using isotopologue pairs of position-specific ${ }^{13} \mathrm{C}$-labeled glucose and pyruvate, Soil Biol. Biochem., 43, 1848-1857, 2011.

Farrar, J., Boddy, E., Hill, P. W., and Jones, D. L.: Discrete functional pools of soil organic matter in a UK grassland soil are differentially affected by temperature and priming, Soil Biol. Biochem., 49, 52-60, 2012.

Fierer, N., Bradford, M. A., and Jackson, R. B.: Toward an ecological classification of soil bacteria, Ecol., 88, 1354-1364, 2007.

Fierer, N., Grandy, A. S., Six, J., and Paul, E. A.: Searching for unifying principles in soil ecology, Soil Biol. Biochem., 41, 22492256, 2009.

Fontaine, S., Mariotti, A., and Abbadie, L.: The priming effect of organic matter: A question of microbial competition?, Soil Biol. Biochem., 35, 837-843, 2003.

Frey, S. D., Lee, J., Melillo, J. M., and Six, J.: The temperature response of soil microbial efficiency and its feedback to climate, Nature Clim. Change, 3, 395-398, 2013.

Gee, G. W. and Or, D.: Particle-size analysis, in: Methods of Soil Analysis, Part 4: Physical Methods, SSSA Book Series No. 5, edited by: Dane, J. H. and Topp, G. C., Madison, Wisconsin, 255-289, 2002.

German, D. P., Chacon, S. S., and Allison, S. D.: Substrate concentration and enzyme allocation can affect rates of microbial decomposition, Ecology, 92, 1471-1480, 2011.

German, D. P., Marcelo, K. R. B., Stone, M. M., and Allison, S. D.: The Michaelis-Menten kinetics of soil extracellular enzymes in response to temperature: A cross-latitudinal study, Global Change Biol., 18, 1468-1479, 2012.

Grayston, S. J., Wang, S., Campbell, C. D., and Edwards, A. C.: Selective influence of plant species on microbial diversity in the rhizosphere, Soil Biol. Biochem., 30, 369-378, 1998. 
Hamer, U. and Marschner, B.: Priming effects in different soil types after addition of fructose, alanine, oxalic acid or catechol, Soil Biol. Biochem., 37, 445-454, 2005.

Hoyle, F. C., Murphy, D. V., and Brookes, P. C.: Microbial response to the addition of glucose in low-fertility soils, Biol. Fertil. Soils, 44, 571-579, 2008.

Jagadamma, S., Mayes, M. A., Zinn, Y. L., Gísladóttir, G. and Russell, A. E.: Sorption of organic carbon compounds in the organomineral fractions of surface and subsurface soils, Geoderma, 213, 79-86, 2014.

Jones, D. L. and Murphy, D. V.: Microbial response time to sugar and amino acid additions to soil, Soil Biol. Biochem., 39, 21782182, 2007.

Kelleher, B. P. and Simpson, A. J.: Humic substances in soils: are they really chemically distinct?, Environ. Sci. Techn ol., 40, 4805, doi:10.1021/es0608085, 2006.

Kelley, A. M., Fay, P. F., Polley, H. W., Gill, R. A., and Jackson, R. B.: Atmospheric $\mathrm{CO}_{2}$ and soil extracellular enzyme activity: a meta-analysis and $\mathrm{CO}_{2}$ gradient experiment, Ecosphere, 2, 120, 2011.

Krull, E. S., Baldock, J. A., and Skjemstad, J. O.: Importance of mechanisms and processes of the stabilisation of soil organic matter for modelling carbon turnover, Funct. Plant Biol., 30, 207-222, 2003.

Kuzyakov, Y. and Cheng, W.: Photosynthesis controls of rhizosphere respiration and organic matter decomposition, Soil Biol. Biochem., 33, 1915-1925, 2001.

Kuzyakov, Y. and Bol, R.: Sources and mechanisms of priming effect induced in two grassland soils amended with slurry and sugar, Soil Biol. Biochem., 38, 747-758, 2006.

Kuzyakov, Y., Hill, P. W., and Jones, D. L.: Root exudate components change residue decomposition in a simulated rhizosphere depending on temperature, Plant Soil, 290, 293-305, 2007.

Lauber, C. L., Strickland, M. S., Bradford, M. A., and Fierer, N.: The influence of soil properties on the structure of bacterial and fungal communities across land-use types, Soil Biol. Biochem., 40, 2407-2415, 2008.

Leake, J. R., Ostle, N. J., Rangel-Castro, J. I., and Johnson, D.: Carbon fluxes from plants through soil organisms determined by field ${ }^{13} \mathrm{CO}_{2}$-labelling in an upland grassland, Appl. Soil Ecol., 33, 152-175, 2006.

Lee, C. K., Barbier, B. A., Bottos, E. M., McDonald, I. R., and Cary, S. C.: The intervalley soil comparative survey: the ecology of Dry Valley edaphic microbial communities, ISME J., 6, 1046-1057, 2012.

Littel, R. C., Miliken, G. A., Stroup, W. W., and Wolfinger, R. D.: SAS System for Fixed Models, SAS Inst. Inc., Cary, NC, USA, 1996.

Loreau, M.: Microbial diversity, producer-decomposer interactions and ecosystem processes: A theoretical model, Proc. R. Soc. Lond. Series B, Biological Sciences, 268, 303-309, 2001.

McGill, W. B.: The physiology and biochemistry of soil organisms, in: Soil Microbiology, Ecology and Biochemistry, 3rd edn., edited by: Paul, E. A., Elsevier Academic Press, Burlington, Madison, 231-256, 2007.

Moore-Kucera, J. and Dick, R. P.: Application of ${ }^{13} \mathrm{C}$-labeled litter and root materials for in situ decomposition studies using phospholipid fatty acids, Soil Biol. Biochem., 40, 2485-2493, 2008.
Nelson, D. W. and Sommers, L. E.: Total carbon, organic carbon, and organic matter, in: Methods of Soil Analysis. Part 3: Chemical methods, SSSA book series No. 5, edited by: Sparks, D. L., Madison, Wisconsin, 961-1010, 1996.

Nguyen, C. and Guckert, A.: Short-term utilisation of ${ }^{14} \mathrm{C}$ [U]glucose by soil microorganisms in relation to carbon availability, Soil Biol. Biochem., 33, 53-60, 2001.

Nottingham, A. T., Griffiths, H., Chamberlain, P. M., Stott, A. W., and Tanner, E. V. J.: Soil priming by sugar and leaf-litter substrates: A link to microbial groups, Appl. Soil Ecol., 42, 183190, 2009.

Orwin, K. H., Wardle, D. A., and Greenfield, L. G.: Ecological consequences of carbon substrate identity and diversity in a laboratory study, Ecology, 87, 580-593, 2006.

Otten, W., Hall, D., Harris, K., Ritz, K., Young, I. M., and Gilligan, C. A.: Soil physics, fungal epidemiology and the spread of Rhizoctonia solani, New Phytol., 151, 459-468, 2001.

Panikov, N. S.: Microbial growth kinetics, Chapman \& Hall, London, p. 378, 1995.

Paterson, E., Gebbing, T., Abel, C., Sim, A., and Telfer, G.: Rhizodeposition shapes rhizosphere microbial community structure in organic soil, New Phytol., 173, 600-610, 2007.

Qiao, N. A., Schaeffer, D., Blagodatskaya, E., Zou, X., Xu, X., and Kuzyakov, Y.: Labile carbon retention compensates for $\mathrm{CO}_{2}$ released by priming in forest soils, Glob. Change Biol., 20, 19431954, 2013.

Rinnan, R. and Bååth, B.: Differential utilization of carbon substrates by bacteria and fungi in tundra soil, Appl. Environ. Microbiol., 75, 3611-3620, 2009.

Rousk, J., Baath, E., Bookes, P. C., Lauber, C. L., Lozupone, C., Caporaso, J. G., Knight, R., and Fierer, N.: Soil bacterial and fungal communities across a $\mathrm{pH}$ gradient in an arable soil, ISME J., 10, 1-12, 2010.

SAS Institute.: The SAS System for Microsoft Windows Release 8.2, SAS Institute, Cary, NC, 2002.

Schädel, C., Luo, Y., Evans, D. R., Fei, S., and Schaeffer, S. M.: Separating soil $\mathrm{CO}_{2}$ efflux into C-pool-specific decay rates via inverse analysis of soil incubation data, Oecologia, 171, 721732, 2013.

Schaeffer, A. M., Billings, S. A., and Evans, R. D.: Laboratory incubations reveal potential responses of soil nitrogen cycling to changes in soil $\mathrm{C}$ and $\mathrm{N}$ availability in Mojave Desert soils exposed to elevated atmospheric $\mathrm{CO}_{2}$, Global Change Biol., 13, 854-865, 2007.

Scharnagl, B., Vrugt, J. A., Vereecken, H., and Herbst, M.: Information content of incubation experiments for inverse estimation of pools in the Rothamsted carbon model: a Bayesian perspective, Biogeosci., 7, 763-776, 2010.

Schimel, J. P. and Schaeffer, S. M.: Microbial control over carbon cycling in soil, Front. Microbiol., 3, 348 pp., 2012.

Schmidt, M. W. I., Torn, M. S., Abiven, S., Dittmar, T., Guggenberger, G., and Janssens, I. A.: Persistence of soil organic matter as an ecosystem property, Nature, 478, 49-56, 2011.

Schneckenberger, K., Demin, D., Stahr, K., and Kuzyakov, Y.: Microbial utilization and mineralization of C-14 glucose added in six orders of concentration to soil, Soil Biol. Biochem., 40, 19811988, 2008. 
Schnitzer, M. and Monreal, C. M.: Quo vadis soil organic matter research?, A biological link to the chemistry of humification, Adv. Agron., 113, 139-213, 2011.

Sollins, P., Homann, P., and Caldwell, B. A.: Stabilisation and destabilisation of soil organic matter: mechanisms and controls, Geoderma, 74, 65-105, 1996.

Strahm, B. D. and Harrison, R. B.: Controls on the sorption, desorption and mineralization of low-molecular-weight organic acids in variable-charge soils, Soil Sci. Soc. Am. J., 72, 1653-1664, 2008.

Strickland, M. S. and Rousk, J.: Considering fungal: bacterial dominance in soil - methods, controls, and ecosystem implications, Soil Biol. Biochem., 42, 1385-1395, 2010.

Strickland, M. S., Lauber, C., Fierer, N., and Bradford, M. A.: Testing the functional significance of microbial community composition, Ecol., 90, 441-451, 2009a.

Strickland, M. S., Osburn, E., Lauber, C., Fierer, N., and Bradford, M. A.: Litter quality is in the eye of the beholder: initial decomposition rates as a function of inoculums characteristics, Funt. Ecol., 23, 627-636, 2009b.

Sutton, R. and Sposito, G.: Molecular structure in soil humic substances: the new view, Environ. Sci. Technol., 39, 9009, 2005.

Thomas, G. W.: Soil pH and soil acidity, in: Methods of Soil Analysis. Part 3: Chemical Methods, SSSA Book Series No. 5, edited by: Sparks, D. L., Madison, Wisconsin, 475-490, 1996.

Trumbore, S. E.: Potential responses of soil organic carbon to global environmental change, Proc. Nat. Acad. Sci., 94, 8284-8291, 1997.

Van Horn, D. J., Van Horn, M. L., Barrett, J. E., Gooseff, M. N., Altrichter, A. E., Geyer, K. M., Zeglin, L. H., and TakacsVesbach, C. D.: Factors controlling soil microbial biomass and bacterial diversity and community composition in a cold desert ecosystem: role of geographic scale, PloS One, 8, e66103, doi:10.1371/journal.pone.0066103, 2013.
Vance, E. D., Brookes, P. C., and Jenkinson, D. S.: An extraction method for measuring soil microbial biomass-C. Soil Biol. Biochem., 19, 703-707, 1987.

von Lützow, M. and Kögel-Knabner, I.: Temperature sensitivity of soil organic matter decomposition-what do we know? Biol. Fertil. Soils, 46, 1-15, 2009.

Wardle, D. A., Bonner, K. I., and Barker, G. M.: Linkages between plant litter decomposition, litter quality, and vegetation responses to herbivores, Funct. Ecol., 16, 585-595, 2002.

Werth, M. and Kuzyakov, Y.: Determining root-derived carbon in soil respiration and microbial biomass using ${ }^{14} \mathrm{C}$ and ${ }^{13} \mathrm{C}$, Soil Biol. Biochem., 40, 625-637, 2008.

Wickings, K., Grandy, A. S., Reed, S., and Cleveland, C.: Management intensity alters decomposition via biological pathways, Biogeochem., 104, 365-379, 2011.

Wickings, K., Grandy, S. A., Reed, S. C., and Cleveland, C. C.: The origin of litter chemical complexity during decomposition, Ecol. Letters, 15, 1180-1188, 2012.

Williams, M. A., Myrold, D. D., and Bottomley, P. J.: Carbon flow from ${ }^{13} \mathrm{C}$-labeled straw and root residues into the phospholipid fatty acids of a soil microbial community under field conditions, Soil Biol. Biochem., 38, 759-768, 2006.

Wu, J., Brookes, P. C., and Jenkinson, D. S.: Formation and destruction of microbial biomass during decomposition of glucose and ryegrass in soil. Soil Biol. Biochem., 25, 1435-1441, 1993.

Zhang, W., Wang, X., and Wang, S.: Addition of external organic carbon and native soil organic carbon decomposition: a meta-analysis, Plos One, 8, e54779, doi:10.1371/journal.pone.0054779, 2013.

Zibilske, L. M.: Carbon mineralization, in: Methods of Soil Analysis. Part 2. Microbiological and biochemical properties, SSSA Book Series 5, edited by: Weaver, R. W., Angel, J. S., and Bottomley, P. S., Madison, Wisconsin, 835-863, 1994. 